\title{
Héroes en los años de entreguerras: las figuras ejemplares según la Revista de Filosofía (Buenos Aires, 1915-1929)
}

\section{Cristina Beatriz Fernández \\ Universidad Nacional de Mar del Plata - CONICET, Argentina}

Recibido: 5/3/2018. Aprobado: 25/6/2018.

\begin{abstract}
Resumen
Nuestro trabajo aborda la colección de la Revista de Filosofía, publicada en Buenos Aires entre 1915 y 1929, fundada por José Ingenieros. La revista fue dirigida por él mismo hasta su muerte en 1925 y, desde entonces, por Aníbal Ponce. Esa revista ha sido estudiada desde diferentes ángulos y suele considerársela un avatar algo tardío del pensamiento positivista en el continente sudamericano. Sin embargo, su proyección en los años posteriores a la primera guerra mundial propicia su articulación con otras zonas ideológicas, como el humanismo de entreguerras, la revolución rusa o la Reforma Universitaria. En ese contexto, nos interesa analizar los artículos y notas que se vinculan con el espacio biográfico (discursos de o sobre personalidades de la cultura, notas de homenaje, noticias necrológicas, reseñas del tipo vida y obra de científicos, escritores o educadores) para esclarecer el modo en que esos textos son funcionales al proyecto cultural que, en líneas generales, suscribe la publicación: un proyecto modernizador, cientificista, secularizador y pacifista.
\end{abstract}

Heroes of the interwar years: the exemplary figures according to the Revista de Filosofia (Buenos Aires, 1915-1929)

\footnotetext{
Abstract

The aim of this paper is to analyse the Revista de Filosofia collection, published in Buenos Aires since 1915 to 1929 . This journal was founded and directed by José Ingenieros and, during the years 1925-1929, by Aníbal Ponce. Many features of the Revista de Filosofía were studied; in general, it is considered a late South American positivist project. On the contrary, this editorial enterprise is developed during the First World War and the post-war era, and that means that the journal takes in consideration other historical situations, for example, the post-war humanism, the Russian Revolution or the Reforma Universitaria movement. Then, we focus on the texts that belong, in a wide sense, to the biographical writing: tribute speeches on some
}

\section{Palabras clave}

José Ingenieros Revista de Filosofía biografías pacifismo modernización

\section{Keywords}

José Ingenieros Revista de Filosofía biography pacifism modernization 


\section{Palavras-chave \\ José Ingenieros Revista de Filosofía biografia pacifismo modernização}

1. De aquí en más, RF.

2. Esta revista fue fundada en 1902 por Francisco de Veyga y la dirigió José Ingenieros, incluso durante su auto-exilio europeo, entre 1911 y 1913, aunque entonces esa función fuese ejercida formalmente por el médico Helvio Fernández. Para la actuación de Ingenieros en revistas: Ardissone et al. (1984), Rossi (1999); Lafleur et al. (2006), Delgado (2009), Pita González (2009), Mailhe (2016), Fernández (2016).

3. Para esta publicación, véase el estudio de Pita González (2009). relevant personalities, obituaries and life-work outlines, all of them devoted to scientists, educators or philosophers. In general terms, all these texts contribute to the main objectives of the journal: to offer models for a scientificist, secularist, modern and pacifist cultural project.

\section{Resumo}

Nosso proposito es estudar a coleção da Revista de Filosofía, publicada em Buenos Aires desde 1915 até 1929. A revista foi fundada por José Ingenieros e foi dirigida por ele mesmo até sua morte em 1925. Desde esse ano até 1929 o diretor foi Aníbal Ponce. A revista foi bastante estudada e muitos vêem em ela um tardio exemplo do positivismo sul-americano. Não obstante, é um projeto dos anos de la primeira guerra mundial e dos seguintes, e isso fa que dialogue cum outros assuntos: o humanismo da época, a revolução russa e o movimento da Reforma Universitaria. Nos interessa estudar os artigos e as notas biográficos, que podem ser discursos de homenagem, necrológios o resumos da vida e da obra de cientistas, escritores ou educadores. Nós acreditamos que esses artigos colaboram nel projeto cultural da revista, orientado para a modernização, a ciência, a secularização e o pacifismo.

Con el inicio de la primera querra mundial, el médico e intelectual José Ingenieros (Palermo, Italia, 1877 - Buenos Aires, 1925) abandonó el autoexilio europeo que se había impuesto en 1911 y regresó a la Argentina. Al año siguiente, en 1915, inició dos proyectos editoriales de envergadura: la colección de libros La cultura argentina y la Revista de Filosofía, Cultura, Ciencias y Educación. ${ }^{1}$ No era el primer proyecto editorial en que se embarcaba Ingenieros, quien se había destacado en la dirección de los prestigiosos Archivos de psiquiatría, criminología, medicina legal y ciencias afines, por citar uno de los ejemplos más notorios entre su prolífica participación en revistas científicas y culturales. ${ }^{2}$ La $R F$ ilustra el cambio de eje disciplinario en la producción de Ingenieros, un investigador precoz de las enfermedades mentales, la medicina legal y la psiquiatría, reconocido por el mundo científico-académico, quien se embarcaba ahora en un proyecto de orientación filosófica que signaría esta última década de su vida. Al decir de Oscar Terán, este giro disciplinario se relacionaba con el desplazamiento de su ideología, desde un individualismo de corte stirneriano hacia la ética social, que recuperaba sus inclinaciones juveniles por el socialismo y que le permitía percibir con entusiasmo la Revolución rusa. Un desplazamiento que lo llevaba desde la ciencia a la educación y la filosofía y que lo vincularía con los ideólogos de la Reforma Universitaria. En esa época, Ingenieros se mostraría influenciado por Emerson y las iglesias liberales norteamericanas, como se puede apreciar en una serie de libros de la misma época: Hacia una moral sin dogmas (1917), Los tiempos nuevos (1921) o Las fuerzas morales (1925), en la línea ya iniciada por su clásico El hombre mediocre (1913). Huelga decir que la guerra, que había puesto en crisis el impulso civilizatorio europeo, también impactó en esta reorientación de las preocupaciones de Ingenieros.

La $R F$ fue un proyecto editorial claramente asociado con el nombre de Ingenieros como figura intelectual rectora, pues además de fundarla fue su gestor principal, autor de muchos de los artículos de la revista y su corrector, aunque contase con colaboradores como Aníbal Ponce, quien la codirigió desde 1923, cuando Ingenieros se concentró en otro proyecto editorial: Renovación. Boletín de Ideas, libros y revistas de América Latina, publicación periódica que fue el órgano de difusión de la Unión Latinoamericana. ${ }^{3}$ Ponce pasó a dirigir la $R F$ en 1925 , el año de la muerte de Ingenieros, hasta el cierre de la revista en 1929. Pero no figura en ninguno de los números el nombre de los integrantes de un consejo editorial o de redacción, solamente el nombre 
del director y del codirector, cuando lo hubo. ${ }^{4}$ Salvo casos excepcionales, la $R F$ se publicaba con frecuencia bimestral y cada número constaba de unas ciento sesenta páginas, aproximadamente. Cada tres números se conformaba un tomo, es decir, que cada año estaba compendiado en dos tomos. Comenzó a salir en enero de 1915 bajo el sello tipográfico de "La Semana Médica - Imp. de Obras de E. Spinelli - Buenos Aires" y más tarde registraría el pie de imprenta de "L. J. Rosso y Cía. impresores". Sabemos que la financiaba el mismo Ingenieros. No era en extremo costosa: la suscripción anual de seis números costaba diez pesos.

El proyecto editorial de la $R F$ exhibe un perfil en alta medida heredero del positivismo, aunque conviven en las páginas de la publicación artículos vinculados al movimiento antipositivista. Recordemos que Ingenieros pretendía una filosofía de base científica y eso explica el lugar concedido a la ciencia y sus practicantes en una publicación que, a juzgar por su título, buscaba encuadrarse primariamente en la filosofía. El peso de las ciencias en este proyecto intelectual y editorial puede inferirse de un párrafo del profesor, abogado y filósofo Rodolfo Rivarola, quien en un artículo de 1915 explicaba lo siguiente: "las ciencias particulares nutren y enriquecen a la filosofía; ésta guía a la política, la cual gobierna por la educación, y por todas ellas esperamos llegar a la realización de la democracia, fórmula del bienestar general" (Rivarola, 1915: 43).

La hegemonía de la perspectiva cientificista se filtra además en artículos de temas diversos, como los educativos o los de tenor historiográfico. Entre estos últimos, se destacan varios del mismo Ingenieros, quien convierte al método científico en una matriz interpretativa de la historia cultural argentina. Así, en su artículo sobre "El contenido filosófico de la cultura argentina", explica el proceso independentista como una escisión respecto de una tradición hispánica que nunca había estado fuertemente marcada por la tradición científica, de modo que la Argentina, en la visión de Ingenieros, se insertaba ab initio en la corriente transnacional de una modernidad que tenía en la ciencia uno de sus baluartes. En sus palabras: "el siglo de oro literario [español] no fue áureo para las ciencias y la filosofía (...) Se comprende, pues, que los colonizadores españoles no trajeran a nuestra América el pensamiento renacentista, sino la escolástica permitida en los claustros peninsulares" (Ingenieros, 1915: 75). Siguiendo la misma línea interpretativa, afirmará que el surgimiento de la nacionalidad argentina fue tributario de un cambio de ideas en las que se había nutrido el grupo criollo que dio lugar a la revolución, y que entre estas ideas tenían lugar preferente las ciencias fisicomatemáticas y los hábitos mentales que propiciaban, porque "todo lo que significaba argentinidad estaba por el libre examen contra el dogmatismo" (Ingenieros, 1915: 97). Por eso, el cambio de los estudios dogmáticos por la "ciencia positiva" equivalía a "substituir al españolismo la argentinidad" (Ingenieros, 1915: 114), un proceso en el cual había sido una figura central Domingo Faustino Sarmiento, cuyo programa educativo y científico se sintetizaba, siempre según el director de la $R F$, en "reemplazar la herencia teológica española por el cultivo de las ciencias de la naturaleza" (Ingenieros, 1915: 131). Otro hito en ese proceso serían las polémicas por la educación laica en el país, pues para Ingenieros y gran parte de los colaboradores de la revista, el pensamiento de matriz experimental y científico era consustancial a la democratización de la política. ${ }^{5}$

El hecho de que se viese en las ciencias y su método una matriz de pensamiento afín a las corrientes filosóficas y políticas modernas, explica no sólo la cantidad de artículos y reseñas de libros dedicados a temas científicos sino también el lugar que se concedía a los escritos biográficos sobre los hombres de ciencia en la revista, sumados, desde luego, a los filósofos, educadores y gestores de instituciones culturales o académicas, siempre en una línea ideológica cuyo sustrato era la secularización de la cultura. En un rastreo transversal a los quince años de la publicación, se puede apreciar la cantidad de artículos orientados, de modos diversos, a la escritura biográfica. Básicamente,
4. Delia Kamia, la hija de José Ingenieros, vincula el proyecto editorial de la RF con una asociación denominada Academia Omnia. Dicha agrupación se habría formado cuando Ingenieros regresó de su segundo viaje a Europa, precisamente en torno de él y conformada por personas inclinadas al estudio e interesadas por diversas disciplinas. Entre los miembros de esa agrupación hay varios personajes cuyos nombres se repiten con frecuencia como autores de los artículos de la RF: Félix Icasate Larios, Aníbal Ponce, Carlos Muzzio Sáenz Peña y Arturo Orzábal Quintana (Kamia, 1968: 226). Cabe recordar aquí que Aníbal Ponce escribía con su nombre o con los seudónimos de Hugo Cáceres, Luis Campos Aguirre, Lucas Godoy, Luis Larrea y Carlos Pirán (Rossi, 1999: 52, nota 83).
5. En las páginas de la misma $R F$, se puede seguir el itinerario de un debate educativo y epistemológico acerca del rol de la educación científica y el problema de la especialización de los saberes, la reformulación de las humanidades y la clase de educación más significativa para los ciudadanos de democracias modernas. Remitimos al lector interesado a Fernández (2012). 
podríamos decir que esas colaboraciones se pueden agrupar en tres clases: necrológicas, artículos del tipo vida-obra y discursos de homenaje. En el primer grupo ubicamos los escritos que están dedicados al elogio de alguna personalidad de la ciencia o la cultura recientemente fallecida o de cuya muerte se cumple algún aniversario. Los segundos son estudios o la reproducción de conferencias que, al analizar la obra de algún personaje, incursionan en la zona del biografismo; son textos que, siguiendo la terminología de Antoine Compagnon y François Dosse, podemos llamar viobra (Dosse, 2007: 53 - 70). En cuanto a los discursos de homenaje, pueden estar destinados a vivos o muertos aunque, en este último caso, no están condicionados por la inmediatez del hecho luctuoso. Estas distintas modalidades de lo biográfico presentan las vidas de sujetos prestigiosos en el campo intelectual como vidas ejemplares, estableciendo lazos simbólicos con los sujetos que las enuncian, ya sea a título personal -un discípulo que elogia la vida de uno de sus maestros, por ejemplo- o involucrando a corporaciones científicas, culturales o profesionales -como el caso de alguien que, en nombre de una academia, despide a uno de sus miembros ponderando su trayectoria-.

Bajo la forma de la recensión bibliográfica del tipo vida-obra, las notas necrológicas o los discusos de homenaje, varios artículos y notas de la $R F$ podrían insertarse en la amplia tradición de la biografía intelectual, cuyos orígenes se remontan a las Vidas de filósofosilustres de Diógenes Laercio y a las múltiples vidas de artistas y poetas que se escribieron desde el Renacimiento hasta el Romanticismo. La clase de biografía que se construye aquí tuvo un precedente importante en tiempos de la ilustración, cuando la figura del científico, en particular del médico, se convirtió en el emblema de la lucha por la libertad de pensamiento y la construcción simultánea de una ciudadanía moderna. El siglo XIX produciría otra inflexión en esa tradición pues, impulsado por la nueva jerarquización de los saberes bajo los influjos de la filosofía positivista, el hombre de ciencia y el educador adquirieron connotaciones heroicas, siempre en clave moderna y secular. Es consustancial a estos escritos, en consecuencia, el peso asignado a los rasgos morales o de personalidad, no tanto a los atributos físicos; se construyen, en gran medida, a partir de la expansión de un recurso retórico básico: la etopeya. En consonancia con esto, si una de las funciones clásicas de la biografía es la de construir un "discurso moral de aprendizaje de virtudes" (Dosse, 2007: 16), las "virtudes" ejemplificadas en la $R F$ son las que demanda el proceso de modernización ideológica y cultural, convirtiendo a los sujetos que las practican en una suerte de héroes culturales, tanto en sentido intelectual como moral.

El elogio a personalidades, a partir de un esquema biográfico, sirve generalmente para ofrecer una perspectiva programática sobre la modernización de la cultura argentina. Un caso que ejemplifica lo antedicho es la conferencia motivada por la muerte de Ernst Haeckel, pronunciada por el Profesor Miguel Fernández de la Universidad de La Plata y reproducida luego en la $R F$, en 1920. En la narración de los hitos sobresalientes de la vida de Haeckel, una vida entendida en términos de productividad científica, se pondera su defensa del transformismo como parte de un debate cultural epocal y se lo inscribe en un linaje de figuras intelectuales cuyo heroísmo es proporcional al desafío a las ideas convencionalmente aceptadas:

Si un hombre del siglo XIX ha sido atacado, lo fue Ernesto Haeckel. ¿Y para qué disimular las causas que indujeron, casi diría, obligaron a los reaccionarios a combatirlo por todos los medios? El transformismo no es una teoría científica cualquiera, es una filosofía que toca muy de cerca todos los aspectos de la vida humana, y además básase en ella el monismo, una Weltanschauung, diré: una nueva religión. ¿No sería entonces más extraño que Haeckel no compartiera la suerte de todos los grandes filósofos profetas: Sócrates, Jesús, Lutero, Espinoza, por no citar sino a unos pocos? (Fernández, 1920: 79. Destacado del autor) 
La idea de que las ideas científicas se proyectan a todos los órdenes de la vida al punto de configurar una nueva visión del mundo, le asigna a la ciencia el lugar de esa "nueva religión", una creencia fundante de la condición moderna. Además, los saberes y prácticas asociados con la ciencia pueden ser la génesis de manifestaciones artísticas e industriales, como lo ilustra el influjo que tuvieron las láminas del clásico libro de divulgación de Haeckel, Formas artísticas de la naturaleza, en el art nouveau. El autor de la conferencia / artículo dice, en un pasaje en que la figura del científico parece evocar la del artista romántico subyugado por la estética sublime de la naturaleza:

\begin{abstract}
Debo aún mencionar, siquiera con algunas palabras, un aspecto del todo original y característico de la obra de Haeckel. Cuando, en compañía de su amigo, el pintor y poeta Allmers viajaba en 1860 por la Sicilia, poco habría faltado para que cambiara de profesión y se hiciera pintor paisajista. El amor por lo bello en la naturaleza lo acompañó durante toda su vida, y por fin en 1900 pudo llevar a cabo un ya viejo deseo y publicar las Formas artísticas de la naturaleza, 100 grandes láminas en que reunió, en forma algo estilizada, las más bellas formas; sinóforos, medusas, corales, moluscos, equinodermos, peces, radiolarios y algas, que tuvo ocasión de observar durante su larga vida. Con esta obra proponíase no solo difundir el gusto por lo bello en el pueblo, sino también poner en manos de los artistas e industriales modelos para un nuevo estilo decorativo. (Fernández, 1920: 85)
\end{abstract}

De la tarea científica irradian, según el pasaje que antecede, distintas expresiones de la cultura moderna, arte e industria incluidos. Y el hecho de que el método científico sea susceptible de universalización, es un aspecto que se asocia con otro rasgo de esa cultura moderna: la internacionalización. Además, es perceptible en varios escritos de la $R F$ el modo en que se vincula el impacto del conocimiento científico con uno de sus efectos colaterales más valorados: su contribución a los procesos de secularización cultural. Brevemente, digamos que la secularización tiene un componente sociopolítico -visible en el ámbito institucional, cuando se separa, por ejemplo, la esfera administrativa clerical de la secular-y otro, que no siempre va acompasado con el primero, que es cultural y que denota la desaparición de la sobredeterminación religiosa de los símbolos propios de la integración cultural. La secularización cultural es un proceso que libera al hombre de visiones del mundo metafísicamente cerradas, a diferencia del secularismo, una ideología que vuelve a ofrecer una visión cerrada del mundo y que funciona, muchas veces, como una nueva religión. La tolerancia ideológica es consustancial al modo de vida secularizado desde el ángulo cultural, así como la desacralización de la política y toda otra manifestación de lo social. ${ }^{6}$ Mundanización y emancipación son, al menos desde el siglo XVIII, dos rasgos asociados con los procesos de secularización, del mismo modo que la concepción autónoma del individuo. ${ }^{7}$

Encontramos una muestra de lo antedicho en el modo en que la $R F$ presenta a cierto sector de la intelectualidad española. En una serie de artículos que luego irían a nutrir el libro La cultura filosófica en España (1922), el mismo Ingenieros ofrece una visión de la cultura española distinta de la defendida por el hispanismo que en esos años se asociaba al nacionalismo tradicionalista en la Argentina. Por el contrario, en la $R F$ parece establecerse una suerte de alianza ideológica transnacional con autores como Adolfo Posada, Rafael Altamira, Miguel de Unamuno o Francisco Giner de los Ríos, cuyo pensamiento respondía, en distintas modulaciones, a las inquietudes despertadas por la crisis del 98. Entre estas figuras, se le concedía un lugar privilegiado a Santiago Ramón y Cajal, presentado como ejemplo de laboriosidad al servicio del trabajo científico, plataforma de acceso para la modernización de España (Galfione, 2015). Varios de estos artículos responden a una concepción misionológica al representar la labor científica, por ejemplo, cuando Gregorio Bermann, en un artículo dedicado al mismo director de la revista, llamaba a seguir "el evangelio de Ramón y Cajal, la
6. Resumimos libremente a Lefebvre 1992 y Cox 1990 para esta síntesis.

7. En su estudio sobre los orígenes de la identidad moderna, Charles Taylor concluye que gran parte de las fuentes que constituyen la subjetividad propia del sujeto moderno son de orden moral - frente a otras interpretaciones que ponen el foco en el orden económico, la producción material o la naturaleza. La noción occidental y moderna del derecho subjetivo, tiene su eje en la naturalización de derechos como la vida y la libertad que, al decir de Taylor, implican la noción de autonomía del sujeto, entendiendo por autonomía su desvinculación respecto de un orden o autoridad superior, su emancipación de la naturaleza y su capacidad de objetivar el mundo que lo rodea. La noción de autonomía se vincula estrechamente con el proceso de secularización, pues escinde al ser humano de su presunto papel en alguna clase de drama cósmico o de plan divino. La independencia respecto de la autoridad impuesta que no excluye la posibilidad, desde luego, de que el sujeto articule nuevas formas de autoridad, mediante diversas construcciones contractuales en las comunidades que integra - así como el énfasis puesto en la responsabilidad individual, el autocontrol del yo y el libre ejercicio de la voluntad son, asimismo, rasgos propios de un sujeto autónomo que, siempre según Taylor, tiene sus orígenes en el pensamiento teológico cristiano y en los debates sobre el libre albedrío y la voluntad que se intensificaron en tiempos de la Reforma. Asimismo, el principio de respeto universal e igualitario, solidario de una concepción moralmente autosuficiente y reflexiva del sujeto, se conecta estrechamente con el concepto moderno de ciencia, por el peso asignado a la razón instrumental así como a la demanda de un compromiso de la voluntad al servicio de un mejoramiento de la condición de la humanidad. Véase Taylor 2006 especialmente 19 - 86, 103,129130, $196-197,245,275-286,526$. 
8. Sobre el tema del heroísmo del científico, véase Ariel Barrios Medina 2000.
Ciencia y el Trabajo" (Bermann, 1926: 207) ${ }^{8}$ Lógicamente, estamos aquí en las huellas del pensamiento regeneracionista del krausismo, para el cual sólo el conocimiento científico permitía transformar la realidad, un objetivo que heredaron los positivistas argentinos (Serna Arnáiz, 1994).

Se trata, en definitiva, de ofrecer al lectorado de la $R F$, un repertorio de vidas ejemplares, como lo ilustra claramente el caso de Francisco Giner de los Ríos, otra de las grandes figuras magisteriales homenajeadas. En una necrológica del año 1915, J. I. -la firma se limita a las inciales- afirma:

Pocas veces, ante un hombre, he tenido la impresión de estar conversando con un santo. No era otra la que me producía, en inolvidable comunión espiritual, Don Francisco, a quien me permitía llamar, equivocándome de intento, San Francisco (...) Por su apostolado cultural, por la modernidad de sus tendencias, por la práctica severa de la virtud, era el hombre más representativo de toda la España intelectual. (Ingenieros, 1915: 311).

El léxico empleado pone en escena uno de los rasgos constitutivos de la biografía moderna, cuando se trata de historias de vida con pretensiones edificantes: su vinculación genealógica con las hagiografías. Ya se ha estudiado cómo en el siglo de las luces surgió el elogio académico, estructurado, en gran medida, a partir de un empleo, profano y secular, de valores transferidos desde la escritura hagiográfica, como los de "devoción" o "sacrificio", que se habían articulado con los de patriotismo y ciudadanía para colaborar en la construcción de una ideología científica moderna (Roche, 1977; Bénichou, 1999: 29). En el párrafo arriba transcripto es muy evidente este procedimiento pero lo es aun más en otra "semblanza", escrita cinco años después en elogio del mismo personaje, nada menos que por la pluma de Alfonso Reyes:

Era un krausista derivado de Sanz del Río, un profesor de Filosofía del Derecho, un escritor, un liberal. Pero nada de eso es importante: era un hombre de temple apostólico. (...) Era un religioso; más bien, un místico; pero a la manera española: cargado de ideales prácticos y positivos. La buena tradición española quiere que la práctica y la mística broten juntas, como en la actual filosofía pragmática. Santa Teresa fundaba monasterios y los sabía regentear. (...) Y San Ignacio de Loyola es un personaje militar: es el militar. (...) En otro siglo, a este viejecito ágil le hubieran llamado San Francisco Giner. Y él mismo comprendía lo místico de su misión. Dicen que él decía ejercer el sacramento de la palabra, y que su función social era hablar. (...) Hablaba para consolar a los afligidos: así, como suena y sin literatura. He oído a más de uno decir, cuando corrió por Madrid la nueva de su muerte. ¿Y a quién llevaremos ahora nuestras dudas íntimas? (...) Ministraba la confesión laica. (...) Ni siquiera le faltó sublevarse, como a buen santo español. Después de ganar una cátedra en la Universidad, renuncia a ella para unirse a los perseguidos. (...) Y he aquí como tampoco le falto fundar una orden. No sé bien si es una orden monástica, pero me parece que es una orden de caballería; aunque tal vez ambas cosas paran en una. Y de aquí proceden los nuevos caballeros de España. (...) Las instituciones que de él proceden directamente forman sin disputa el grupo avanzado de la cultura española. Este hombre se ha multiplicado como una divinidad indostánica (...) Si Francisco Giner no está precisamente en el origen de todas las orientaciones actuales, es indiscutible que todos los hilos han pasado por sus manos. (...) (Reyes, 1920: 67-69)

Recordar en estos términos al fundador de la Institución Libre de Enseñanza y de la Residencia de Estudiantes, filósofo y pedagogo crucial en la formación de varias generaciones de la España moderna -al menos, hasta el advenimiento del franquismo-, era una forma de ofrecer modelos para la gestión cultural, sustituyendo la posición directriz de la cultura católica -ineludible en el contexto español y, por 
derivación, hispanoamericano- por estos nuevos santos laicos y sus seguidores seculares, dedicados no ya a cultivar una fe heredada sino a combatir, en el orden práctico, los obstáculos para la instalación de formas culturales modernas. ${ }^{9}$ Eso se hace explícito en la reseña de un libro de Juan Chiabra, en la cual se sostiene que "la ciencia representa la destrucción pacífica pero segura del prejuicio (...) en la actuación superior de las clases dirigentes, es indispensable una cultura científica que solamente las ciencias filosóficas, psicológicas, sociales e históricas pueden dar (...)" (Chiabra, 1915: 172). En una cita como la que precede, observamos la perspectiva, de matriz positivista, de un cientificismo entendido como extensión del método científico a todos los dominios de la vida intelectual y moral (Schuster, 1985: 321-322).

En consonancia con esta perspectiva, la $R F$ se esmeraba, tanto en la sección de artículos principales como en la de reseña de bibliografía, en ofrecer una imagen de actualización en materia científica y de conexión con las novedades científicas internacionales, no sólo argentinas o españolas. En lo que hace a las notas de tenor biográfico, esto era visible en el espacio concedido a figuras como Theodule Ribot, Félix le Dantec, Augusto Pi y Suñer -que además escribió en la revista-, Pierre Marcellin Berthelot, Ernesto Haeckel o Enrico Morselli, además del caso de visitantes ilustres que pasaron por la Argentina en esos años, como Einstein en 1925. Lo que resulta evidente es que los sujetos involucrados en la tarea intelectual se rigen, en la mayoría de las notas y artículos de la revista, por valores universales, como los de razón o verdad que, a la vez, son valores en sí mismos racionales y desinteresados (Cfr. Benda, 2008: 77). Sin embargo, y a diferencia de esa independencia respecto de los fines pragmáticos que Julien Benda consideraba definitoria de sus intelectuales -pues para él, el intelectual o clerc dejaba de serlo desde el momento en que se ponía al servicio de una idea o valor no universal, como los nacionalismos y otras formas gregarias y políticas- los sujetos cuyas vidas son elogiadas en la $R F$ son ponderados, precisamente, por haber colaborado en la construcción de saberes, prácticas sociales o instituciones de carácter colectivo y con impacto en la vida social, como lo ilustra claramente el caso de Francisco Giner.

En relación con la construcción, en las páginas de la $R F$, de una comunidad intelectual y sus afanes de internacionalización, merece una atenta lectura el artículo que el mismo Ingenieros le dedicó al "biólogo y filósofo" Félix Le Dantec, que además de reseñar vida y obra del científico, ilustra simultáneamente parte de sus redes de vinculación con la ciencia europea, en este caso, francesa: Ingenieros se presenta a sí mismo como un receptor privilegiado de las novedades científicas europeas y también se inscribe en el meritorio y selectivo grupo de los latinoamericanos leídos y elogiados por Le Dantec. Al analizar la producción de Le Dantec, nuestro autor la divide en dos grandes secciones, los libros genuinamente científicos y otros de difusión o escritos "con fines polémicos", de los cuales afirma que

Los libros de este segundo grupo son, naturalmente, los que han reclutado a Le Dantec una hueste de admiradores y detractores, vírgenes, unos y otros, de todo contacto pecaminoso con las ciencias. Sin conocer sus obras realmente científicas, le admiran los lectores de Büchner y de Haeckel, o le detestan los de Bergson y Bourget; aquellos y éstos, como sabéis, reclutan su clientela entre los ignorantes que creen que la ciencia ha resuelto todos los enigmas, y los ignorantes que opinan que todos ellos pueden ser resueltos con artísticas elucubraciones. (...) (Ingenieros, 1917: 274)

Al discriminar el genuino valor científico en la desigual producción de Le Dantec, Ingenieros se presenta, a la vez, como un lector calificado y un mediador cultural de esas novedades científicas para el lectorado de la $R F$. Esto es posible porque a lo largo de ese escrito biográfico -originalmente una conferencia para estudiantes de medicina- nuestro autor construye, especularmente, su propia imagen como un
9. Tomamos la expresión “santos laicos” de Podgorny 1997. 
10. Algunos aspectos del diseño y la edición de la RF contribuyen a la construcción de un objeto cultural de corte más tradicional, en el sentido de que deja poco espacio a la exhibición de adelantos tecnológicos, como la fotografía. Los veintinueve volúmenes que integran la colección tienen un formato más similar al de un libro que al de un diario o folleto. La distribución del texto es consistente con ese diseño: no hay columnas que organicen el texto, $\mathrm{ni}$ ilustraciones, nunca una imagen en color. Solamente aparecen cuatro fotografías en los quince años de la revista: la de Carlos Octavio Bunge en 1918, la de Ramón Turró en 1919, la de Luis María Drago en 1921, la de Joaquín V. González en 1924. La revista invita, en consecuencia, a una modalidad de lectura propia del libro, dado el predominio de la linealidad de las grandes masas textuales. Sobre cuestiones concernientes a las revistas como objeto de análisis: Artundo 2010 Delgado 2014; Pita y Grillo 2015. receptor local de las ideas científicas europeas, recepción que llegado el momento derivará en una producción innovadora, la cual será legitimada, circularmente, por el mismo Le Dantec. Así, Ingenieros introduce una nota de autobiografismo cuando invita a su auditorio a

(...) recordar que en la época de su aparición [del Tratado de Biología, de Le Dantec, 1903] publiqué algunos análisis de la obra en nuestras revistas médicas, reconociendo que, en ese entonces, me parecía una de las más felizmente realizadas entre sus similares. Agregaré que en 1907, como introducción al estudio de la psicología, dediqué catorce conferencias, en mi cátedra de la Facultad de Filosofía, al examen de los catorce capítulos que componen la obra (...) (Ingenieros, 1917: 298)

para agregar de inmediato: "Los que hayan leído a Le Dantec y mis Principios de Psicología podrán apreciar algunas provechosas sugestiones que recogí en su obra para un capítulo de la mía que estudia 'la energética biológica', aunque advertirán la manera completamente diversa con que he planteado los fundamentos de la psicología" (Ingenieros, 1917: 298). A continuación, cita el elogio que había recibido de parte de Le Dantec, al publicarse la edición francesa de su libro.

La posibilidad de que las figuras reseñadas cumplan con este papel magisterial, se debe, en gran medida, a la concepción positivista todavía vigente en sus páginas, que le asigna a la ciencia y a la educación un rol que excede los saberes específicos y la dimensión técnica. La ciencia, podría decirse, cumple un papel civilizatorio en el marco de procesos culturales más amplios, resulta ser algo así como la punta de lanza de la secularización intelectual y social, un proceso que para el núcleo de colaboradores de la $R F$ es consustancial al acceso a la modernidad cultural. No obstante, hay un aspecto de ese proceso de la modernidad, la modernización tecnológica, que no tiene la misma cabida en la $R F$. Vale recordar aquí lo que advertía Harvey Cox respecto de las metrópolis modernas, que no eran ciudades diferenciadas de las antiguas sólo por su tamaño, sino que se conformaban, en realidad, como tecnópolis, es decir, espacios en los cuales el desarrollo tecnológico tenía un lugar cada vez más destacado (Cox 1990). En la ciudad de Buenos Aires, en los años en que se desarrollaba el proyecto de la $R F$, los cambios en el paisaje urbano ejemplificaban el estatuto de esa "modernidad periférica" descripta por Beatriz Sarlo y entre cuyos rasgos se destacaban el cosmopolitisimo, la presencia de publicaciones periódicas diversificadas en su lectorado y la aparición de la radiofonía. En palabras de Sarlo:

El mundo y la vida de los intelectuales cambia aceleradamente en los años veinte y treinta: al proceso de profesionalización iniciado en las dos primeras décadas de este siglo, sigue un curso de especificación de las prácticas y diferenciación de las fracciones. Los intelectuales ocupan un espacio que ya es propio y donde los conflictos sociales aparecen regulados, refractados, desplazados, figurados. (...) La ciudad misma es objeto del debate ideológico-estético: se celebra y se denuncia la modernización, se busca en el pasado un espacio perdido o se encuentra en la dimensión internacional una escena más espectacular. (Sarlo, 1988: 28)

Está claro que, entre la huida al pasado o la búsqueda de una escena internacional, la $R F$ opta por lo segundo. En cuanto a la dimensión tecnológica asociada al avance científico, son escasas las referencias en la revista, con excepción de algunos artículos sobre el lugar de la técnica en la educación universitaria -la inauguración de laboratorios, por ejemplo-y los debates por los contenidos de la educación en el marco de la Reforma Universitaria. ${ }^{10}$ En consecuencia, la visión de la ciencia y de la figura del científico, es una visión heredera del optimismo ilustrado, un optimismo que había sobrevivido en la vertiente del romanticismo social y que había llegado tanto a las utopías del socialismo como a esa romantización de la ciencia que, en gran medida, fue el cientificismo positivista. Pero, por otro, 
ya en las segunda y tercera décadas del siglo XX era dificultoso ignorar la percepción negativa de algunos rasgos de la ciencia en ese período contemporáneo a la Primera Guerra Mundial y su consiguiente posguerra, período que había puesto en crisis ese mismo optimismo ilustrado sobre el desarrollo científico y el avance tecnológico. La $R F$ construirá, en esta línea, una defensa del pacifismo que reflexionará, además, sobre la práctica científica, poniéndola al margen de toda culpabilidad en el proceso de la Gran Guerra. Por ejemplo, mientras en la sección principal de la revista aparecen artículos que buscan explicar la teoría de la relatividad, en la sección de "Bibliografía" tendrá cabida el discurso de Alberto Einstein "La Ciencia y el Pacifismo", publicado originalmente en Clarté, París, el 18 de enero de 1922. Recordemos que el grupo Clarté, que incorporaba entre otros intelectuales a Henry Barbusse, Anatole France, Vicente Blasco Ibáñez, Jules Romain, Upton Sinclair, Herbert George Wells y Stefan Zweig, había sido fundado en París en 1919 y logró convocar a figuras de otros países. Rechazaba la Primera Guerra y el consiguiente Tratado de Versalles y simpatizaba con la revolución rusa. Fabio Moraga Valle ha señalado, precisamente, que muy probablemente fue José Ingenieros el primer intelectual rioplatense en tomar contacto con la Internacional del Pensamiento promovida por el grupo Clarté (Moraga Valle, 2015 y 2016).

La lectura de los textos biográficos de la $R F$-en las variantes que intentamos sistematizar anteriormente- en diálogo con estos otros intereses de la publicación, nos permite apreciar el modo en que los conflictos de orden histórico o social son presentados en forma selectiva. Por un lado, para Ingenieros y el núcleo de colaboradores de la $R F$, la ciencia parecía ofrecer una plataforma cognitiva y moral apta para lidiar con los conflictos que planteaba la modernidad. Por otro, sus páginas están plagadas de homenajes a hombres de ciencia y educadores. No obstante, no podemos considerar que estamos, simplemente, ante un proyecto positivista algo tardío en el tiempo, pues la relación obliterada con la dimensión tecnológica y la inscripción del pacifismo de entreguerras nos ofrecen una pista que no conviene desestimar. La irrupción de la guerra hace que la actividad científica y con ella, sus practicantes, deban abandonar el rol de liderazgo cultural para, muchas veces, tener que posicionarse a la defensiva. Enfrentándose a las voces que consideraban que el desarrollo tecnológico había causado o, al menos, posibilitado, la tragedia de la guerra del 14, la $R F$ se vuelca en justificar el desarrollo científico y presentarlo como una actividad pacifista y moralmente educadora, lo cual permite leer estos escritos biográficos en otra clave, muy sensible a los problemas de su época. En 1917, en plena guerra mundial, el célebre pedagogo de orientación positivista Víctor Mercante dedicaba un artículo a la memoria de Florentino Ameghino, muerto seis años antes, que justificaba en estos términos: "Conmemorar a un hombre de ciencia es clavar una bandera de paz en la historia. Nunca tan necesitados, como ahora, de amor" (Mercante, 1917:351). Incluso en una recensión bibliográfica firmada por J. I. y dedicada al escrito de Francisco R. Canosa, "Al margen de la gran tragedia", que había sido publicado en Ideas y figuras (Buenos Aires, enero 27 de 1915), se aprovechaba la ocasión para sentar una posición antibelicista:

Los hombres de ideales modernos deben desinteresarse de este conflicto en que no pugnan la Cultura y el Trabajo contra las fuerzas reaccionarias, sino un militarismo contra otro, una hegemonía contra otra, un viejo régimen contra otro viejo régimen. Los verdaderos pacifistas, que predicaron siempre la guerra a la guerra, sólo pueden apasionarse y luchar por altos ideales humanos, por ideales de justicia y de solidaridad. (J. I., 1915: 329-330)

Otra nota, firmada por Pedro Escasán, llegaba a cifrar el origen de la guerra en la escasa difusión de la cultura científica, estableciendo una ecuación en la que el pacifismo era directamente proporcional al desarrollo de la ciencia (1915: 488 - 489). A esto se suma que en el año 1921, se publicó dos veces, en el número 1 y en el número 3, el 
11. Por si fuera poco, los eventos internacionales habían impactado en la realidad porteña y, con ello, en la vida de la revista y su director: en noviembre de 1918 , Ingenieros había brindado una conferencia sobre el movimiento maximalista en el Teatro Nuevo de Buenos Aires, conferencia que derivó en manifestaciones e incidentes, a favor y en contra. En 1919, el impacto económico de la guerra fue causa de una crisis económica local, que se complicó con las huelgas obreras y la consecuente represión estatal que caracterizaron la "Semana Trágica". Según declaraciones de su hija, la asociación de la conferencia de Ingenieros con los eventos del año 1919 colocó a este último en la mira de los servicios de seguridad: "En el transcurso de un año habitó en cinco o seis casas diferentes en la capital o sus alrededores" (Kamia, 1957: 122). Una huella de ese complejo momento está en la sección de reseñas bibliográficas de la revista, pues se encuentra ausente en todos los números del primer semestre y en el primero del segundo semestre del año 1919. La explicación es que el responsable de completar la sección era el mismo Ingenieros.
Manifiesto al pueblo de la República, con motivo de la situación internacional, promulgado en 1920 por la Federación Universitaria Argentina, en el que se cuestionan abiertamente la querra y el Tratado de Versalles. ${ }^{11}$

Además de dar cabida en sus páginas a las comunicaciones del grupo Claridad, Ingenieros publicó en la revista la encuesta que, en el año 1923, le dirigió la Comisión de Cooperación Intelectual de la Sociedad de las Naciones, presidida por Henri Bergson, en la cual le preguntaban por la actividad intelectual en la Argentina en los últimos diez años. Al responder esa encuesta, el director de la $R F$ ofrecía un verdadero ejercicio de sociología del campo científico y cultural, en el contexto de la posguerra. Sin ambages, respondía cuestionando a la misma Comisión que le había hecho llegar la encuesta afirmando que

Esa Comisión recurre a una perífrasis superflua, al referirse a la última decena de años; lo que se propone averiguar es la influencia de la guerra y la postguerra sobre el desenvolvimiento intelectual. Si la pregunta hubiera sido formulada con claridad, en ella estaría contenida la respuesta. La vida intelectual argentina, como, en general, la de toda la América Latina, es un joven gajo de la intelectualidad europea, con las variantes impresas en ella por nuestra propia constitución sociológica; en tal sentido a nadie sorprenderá que, en diversa escala, la actividad intelectual en el dominio de las investigaciones científicas haya sufrido un estancamiento, si no un retroceso, lo mismo que en toda Europa; ese fenómeno se debe a la guerra y a sus consecuencias ulteriores, y lo único que podría hacerse por el progreso de los altos estudios en el mundo sería contribuir a la desmovilización de los espíritus. (Ingenieros, 1923: 2. Destacado del autor)

Para Ingenieros, el fenómeno de la guerra era una muestra cabal de la inserción de la Argentina en los procesos de la modernidad occidental, pues el país había padecido, al igual que Europa, el retroceso en varias disciplinas, excepto en "las ciencias aplicables por los estados beligerantes a las industrias de la guerra, como la química, la aviación o la cirugía" e incluso en meritorios casos aislados, como el de Einstein, nuestro autor afirma que sus "doctrinas son un resultado natural y legítimo de estudios e investigaciones iniciados antes de la guerra" (Ingenieros, 1923: 2-3). Para colmo de males, la propaganda bélica de países como Francia y Alemania había sido causa, siempre según Ingenieros, de la "corrupción del espíritu científico por el patrioterismo" y de que "los escritores científicos o literarios" argentinos que colaboraban en revistas europeas lo hacían en el marco de una "hospitalidad (...) tendenciosa, encaminada a consolidar las amistades nacidas o acentuadas durante la guerra" (Ingenieros, 1923: 4). Asimétricamente, señalaba que en las revistas argentinas -entre las que presumimos contaba a la propia $R F$ - era "excelente la información periodística sobre la vida intelectual europea". En una lectura claramente geopolítica de las condiciones del trabajo científico, Ingenieros analizaba en esa encuesta la influencia científica de Francia, Alemania, Italia, Estados Unidos y España. Decía que las relaciones con colegas de estudio europeos se habían reducido durante la guerra, "aunque empezaron a circular entre nuestros intelectuales las Cruces de Hierro y Legiones de Honor con que Alemania y Francia han estimulado a sus partidarios, por razones de política más bien que por estimación intelectual" (Ingenieros, 1923: 10). Advertía, además, que la "penetración intelectual" de EE.UU. en América Latina era resistida como efecto derivado de su política imperialista y, tomando en consideración que los factores lingüísticos no son menores a la hora de establecer jerarquías disciplinarias y circuitos de difusión, señalaba que Argentina estaba en posición de influir en América Latina pero no así en el desenvolvimiento científico europeo, porque su idioma era el español.

En resumidas cuentas, los conflictos políticos de los años de la guerra y la posguerra aparecen explícitos en la $R F$, y es ese contexto el que le otorga otro valor y significación 
a la dimensión biográfica inscripta en tantas notas necrológicas, artículos y discursos de homenaje. Si los procesos de secularización y de modernización tenían un norte en la emancipación del individuo, sobre la base de una concepción autónoma del sujeto, la necesaria reformulación de un nuevo humanismo en los años de la entreguerra ponía en crisis una serie de variables, como la fe en la ciencia, el progreso y el desarrollo tecnológico, otrora celebrados. ${ }^{12}$ De ahí que sea consistente con la perspectiva ideológica de la publicación la obliteración de la dimensión tecnológica y, en lo que hace al espacio biográfico, la conmemoración de más descubridores que inventores. Las figuras elegidas para ser presentadas como dignas de ejercer el magisterio intelectual y moral se sostenían en una legitimidad cultural basada en la meritocracia, la laboriosidad e, incluso, cierta ascesis que se había desplazado del terreno religioso al ámbito secular. El capital simbólico acumulado por estos trabajadores intelectuales, excedía sus especialidades disciplinarias y autorizaba su intervención en el orden político y social (Charle, 2009: 25). El desarrollo tecnológico, en parte desacreditado por la guerra, parece algo escindido de este proyecto editorial, a pesar de que en el contexto de esa modernidad periférica, para retomar la imagen de Sarlo, la técnica tuviese un peso significativo en el imaginario popular, incluso como posibilidad democratizadora frente a los saberes científicos de la cultura letrada o como núcleo genésico de la fabulación en torno de la invención (Sarlo, 2004). Se trataba, de algún modo, de cerrar filas en torno a los aspectos de la tarea educacional y científica menos susceptibles de ser cuestionados, ante el embate de filosofías anticientificistas que podían propiciar, a su vez, el resurgimiento de propuestas culturales antisecularizadoras. Para decirlo de otro modo, si se asocia la secularización con la superación cultural de módulos de pensamiento propios de una época precientífica y la posibilidad de generar un humanismo centrado en la autonomía responsable del individuo, desconfiar de los efectos no deseados del avance científico y tecnológico se convertía en una verdadera amenaza cultural. Por ello, las vidas de estas figuras ejemplares eran presentadas en forma laudatoria y con una finalidad ejemplificadora, apelando a modos discursivos y retóricos de antigua tradición pero reescribiendo las res gestae de estos nuevos héroes bajo el signo de los valores positivos de la modernidad y obliterando aquellos aspectos que alimentaban el debate antimoderno y anticientifico.

Una interpretación posible, como ya dijimos, es que la $R F$ ofrecía un producto editorial anclado en un movimiento filosófico y cultural algo pasado de moda. Nos resulta, sin embargo, ingenuo suponer eso, a la luz de su explícita posición en relación con los grandes problemas de su tiempo, pues la línea editorial de la $R F$ intervino ostensiblemente en la esfera pública defendiendo la Reforma Universitaria, recibiendo alborozada la revolución rusa de 1917 o criticando la cada vez más visible política panamericanista de los Estados Unidos en América Central. En todo caso, cabría pensar que este proyecto editorial redoblaba su apuesta en favor de la racionalización de la conducta, la destrucción del prejuicio y el antibelicismo, ejemplificando esas virtudes con las historias de vida de los hombres de ciencia y educadores que proponía como modelos, quienes se convertían, así, en héroes al servicio de una nueva causa, la del pacifismo de entreguerras.
12. En línea con las menciones anteriores a los atributos que, al decir de Charles Taylor, son conexos a la autonomía, conviene señalar aquí que el ideal del yo moderno fue tributario del modo en que se desarrolló la cosmovisión científica, al propiciar no sólo la objetivación del mundo que rodea a ese sujeto moderno sino también sus emociones y pulsiones. En ese sentido, la racionalidad intrínseca al proceso de objetivación del mundo que es consustancial a la ciencia moderna, no debe entenderse sólo como un modo de entender o ver un cierto orden del cosmos, sino que es esencialmente procedimental y tiene su correlato en la dimensión del autodominio o del autocontrol del yo, siempre según premisas racionales (Taylor 2006: $44-45$ ). De allí que el poner en cuestión los avances científicotecnológicos, en virtud de su papel en la contienda bélica, derivase implícitamente en una amenaza a la concepción occidental y moderna de la condición humana deseada. 


\section{Bibliografía}

» Altamirano, C. (director) (2008). Términos críticos de sociología de la cultura. Buenos Aires: Paidós.

" Ardissone, E., Sassi, R., Biagini, H. (1984). La Revista De Filosofía (1915-1929): Estudio e índices analíticos. Buenos Aires: Academia Nacional de Ciencias de Buenos Aires / Centro de Estudios Filosóficos.

»Artundo, P. M. (2010). "Reflexiones en torno a un nuevo objeto de estudio: las revistas". En IX Congreso Argentino de Hispanistas. El hispanismo ante el bicentenario. En línea: <http://www.memoria.fahce.unlp.edu.ar/trab_eventos/ev.1028/ ev.1028.pdf>.

»Benda, J. (2008 [1927]). La traición de los intelectuales. Traducción de Rodolfo Berraquero. Nota de Fernando Savater. Barcelona: Galaxia Gutenberg / Círculo de lectores.

» Bénichou, P. (1999 [1973]). The Consecration of the Writer, 1750-1830. Translated by Mark Jensen. Nebraska UP.

"Chiabra, J. (1915). “'Función de las facultades de filosofía en la cultura superior' (Revista Argentina de Ciencias Políticas), Buenos Aires, diciembre, 1914”. Reseñado en: Revista de Filosofía, año I, núm. 1, pp. 169-173.

"Barrios Medina, A. (2000). "Somos misioneros entre gentiles. Una perspectiva misionológica de la ciencia”. En Marcelo Montserrat (compilador). La ciencia en la Argentina entre siglos. Textos, contextos e instituciones. Buenos Aires: Manantial, pp. 145-155.

»Bermann, G. (1926). “La filosofía de Ingenieros”. En Revista de Filosofía, año XII, núm. 1, pp. 178-231.

»Carlyle, T. (1951 [1841]). Los héroes. Traducción de F. Gallach Palés. Buenos Aires: Espasa-Calpe.

»Charle, Ch. (2009 [1990]). El nacimiento de los “intelectuales”. 1880-1900. Traducción de Heber Cardoso. Buenos Aires: Nueva Visión.

" Cox, H. (1990 [1965]). The Secular City. Secularization and Urbanization in Theological Perspective. Macmillan.

»De Diego, J. L. (director) (2014). Editores y políticas editoriales en Argentina (18802010). Buenos Aires: FCE.

"Delgado, V. (2009). El nacimiento de la literatura argentina en las revistas literarias (1896-1913). La Plata: EDULP.

»Delgado, V. (2014). "Algunas cuestiones críticas y metodológicas en relación con el estudio de revistas". En Delgado, V., Mailhe, A. y Rogers, G. (coordinadoras). Tramas impresas. Publicaciones periódicas argentinas (siglos XIX - XX), pp. 11-25. La Plata: Edulp. En línea: <https://www.libros.fahce.unlp.edu.ar/index. php/libros/catalog/book/33>.

"Dosse, F. (2007). El arte de la biografía: entre historia y ficción. México: Universidad Iberoamericana.

"Ehrlicher, H., Rissler-Pipka, N. (editores) (2014). Almacenes de un tiempo en fuga: revistas culturales en la modernidad hispánica. Aachen: Shaker Verlag. 
»Einstein, A. (1922). “La Ciencia y el Pacifismo”. En Revista de Filosofía, año XV, núm. 2, pp. 316-317.

»Escasán, P. (1915). “José Torralvo. Moral filosófica de la evolución (Estudios, Rosario, abril, 1915)”. Reseñado en: Revista de Filosofía, año I, núm. 3, pp. 488-489.

»Fernández, C. B. (2015). “La construcción de la imagen del intelectual en las notas necrológicas de la Revista de Filosofía”. En Latinoamérica, núm. 60, 187-206.

»Fernández, C. B. (2016). “A través de lecturas: la conformación de una red intelectual en la sección bibliográfica de la Revista de Filosofía (1915-1922)". En Pita González, A. (coord.). Redes intelectuales transnacionales. Prácticas y soportes culturales durante la entreguerras en América Latina, pp. 193-218. México: Porrúa.

» Fernández, C. B. (2012). José Ingenieros y los saberes modernos. Córdoba: CEA UNC / Alción.

»Fernández, M. (1920). "En la muerte de [E]rnesto Haeckel (17 de febrero de 1834 - 8 de agosto de 1919)". En Revista de Filosofía, año VI, núm. 1, pp. 79-93.

»France, P. (2002). “From Eulogy to Biography: The French Academic Eloge”. En France, P. and St. Clair, W. (editors). Mapping Lives. The Uses of Biography, pp. 83-102. Oxford, The British Academy / Oxford University Press.

» Galfione, M. C. (2014). "Razones de una revista, razones de una filosofía. La Revista de Filosofía como proyecto colectivo, disciplinar y político", ponencia leída en el II Congreso de Historia Intelectual de América Latina, organizado por el Centro de Documentación e Información de la Cultura de Izquierda (CEDIN$\mathrm{CI}$ ), la Universidad Nacional de San Martín (UNSAM) y el Centro de Historia Intelectual (CHI) de la Universidad Nacional de Quilmes, Buenos Aires, 12 al 14 de noviembre de 2014.

» Galfione, M. C. (2015). “Diferencias de origen. La filosofía española según la Revista de Filosofía” (mimeo).

》 Garraty, J. (1964). The Nature of Biography. London: Vintage Books.

» Graciano, O. (2008). Entre la torre de marfil y el compromiso político. Intelectuales de izquierda en la Argentina, 1918-1955. Bernal: UNQ.

»Ingenieros, J. (1915). “El contenido filosófico de la cultura argentina”. En Revista de Filosofía, año I, núm. 1, pp. 73-147.

»Ingenieros, J. (1917). “Le Dantec, biólogo y filósofo”. En Revista de Filosofía, año III, núm. 5, pp. 267-328.

»Ingenieros, J. (1923). “Encuesta sobre cooperación intelectual”. En Revista de Filosofía, año IX, núm. 4, pp. 1-11.

»Ingenieros, J. Ponce, A. (directores) (1915-1929). Revista de Filosofía. Buenos Aires.

» Ingenieros, J. (1915). “Don Francisco Giner de los Ríos. Falleció en Madrid el 18 de febrero de 1915”. En: Revista de Filosofía, año I, núm. 2, pp. 311-314.

»Ingenieros, J. (1915). “Francisco R. Canosa. Al margen de la gran tragedia”. Reseñado en Revista de Filosofía, año I, núm. 2, pp. 329-330.

» Julliard, J. (1987). “Le monde des revues au début du siècle. Introduction”. En Cahiers George Sorel, núm. 5, pp. 3-9.

»Kamia, D. (1957). Entre Yrigoyen e Ingenieros (un episodio de la Historia Argentina contemporánea). Buenos Aires: Meridión.

» Kamia, D. (1968). “La Syringa”. En VVAA, Sociedades literarias argentinas (1864- 
1900). Trabajos, comunicaciones y conferencias, Volumen IX, pp. 203-226, La Plata, Departamento de Letras de la Facultad de Humanidades y Ciencias de la Educación de la Universidad Nacional de La Plata.

»Lafleur, H., Provenzano, S., Alonso, F. (2006). Las revistas literarias argentinas (1893-1967). Ensayo preliminar de Croce, M. Buenos Aires: El 8vo. Loco.

»Lefébvre, S. (1992). “Secularidad”. En Latourelle, R. y Fisichella, R. (editores). Diccionario de Teología fundamental, pp. 1320-1335. Madrid: San Pablo.

» Lértora Mendoza, C. (1985). "Ciencia y filosofía en Ingenieros”. En Biagini, H. E. (comp.). El movimiento positivista argentino, pp. 539-556. Buenos Aires: Editorial de Belgrano.

»Mailhe, A. (2014). "Vínculos intelectuales y conceptualizaciones de la alteridad en revistas científicas de entresiglos", ponencia leída en el II Congreso de Historia Intelectual de América Latina "La biografía colectiva en la historia intelectual latinoamericana", organizado por el Centro de Historia Intelectual de la Universidad Nacional de Quilmes (UNQ), el Centro de Documentación e Investigación de la Cultura de Izquierdas en la Argentina (CEDINCl) y la Universidad Nacional de San Martín (UNSAM), Buenos Aires, 12 al 14 de noviembre de 2014.

"Mailhe, A. (2016). Archivos de psiquiatría y criminología 1902-1913: concepciones de la alteridad social y del sujeto femenino. La Plata, Universidad Nacional de La Plata - Facultad de Humanidades y Ciencias de la Educación - Biblioteca Orbis Tertius. Disponible en <http://bibliotecaorbistertius.fahce.unlp.edu.ar/11.\%20 Mailhe.pdf>.

" Mercante, V. (1917). “Los valores morales de Ameghino”. En Revista de Filosofía, año III, núm. 6, pp. 345-352.

» Moraga Valle, F. (2015): "El resplandor en el abismo: el movimiento Clarté y el pacifismo en América Latina (1918-1923)". En Anuario Colombiano de Historia Social y de la Cultura, 42, núm. 2, pp. 127-159.

»Moraga Valle, F. (2016). “Un resplandor en el Nuevo Mundo: la red Clarté y el pacifismo en América Latina, 1918-1938”. En Pita González, A. (coordinadora). Redes intelectuales trasnacionales en América Latina durante la entreguerra, pp. 51-78. México: Porrúa.

» Pita González, A. (2009). La Unión Latinoamericana y el Boletín Renovación: redes intelectuales y revistas culturales en la década de 1920. México: El Colegio de México / Centro de Estudios Históricos / Universidad de Colima.

»Pita González, A. (2009). “Los homenajes a José Ingenieros y el debate en torno al papel del intelectual”. En Revista Complutense de Historia de América, núm. 35, pp. 69-85.

»Pita González, A. y Grillo, M. del C. (2015). “Una propuesta de análisis para el estudio de revistas culturales”. En RELMECS, vol. V, núm. 1. Disponible en: $<$ www.relmecs.fahce.unlp.edu.ar>.

»Podgorny, I. (1997). “De la santidad laica del científico Florentino Ameghino y el espectáculo de la ciencia en la Argentina moderna". En Entrepasados. Revista de Historia, vol. 6, núm. 3, pp. 37-61.

»Rivarola, R. (1915). “Filosofía, política y educación”. En Revista de Filosofía, año I, núm. 1, pp. 31-43.

» Roche, D. (1977). “Talents, raison et sacrifice (L'image du médecin des Lumières d'après les Éloges de la Société Royale de Médecine (1776 - 1789))". En Annales. Économies, Sociétés, Civilisations, vol. 32, núm. 5, pp. 866-886. 
»Reyes, A. (1920). “Don Francisco Giner de los Ríos (semblanza)”. En Revista de Filosofía, año Vl, núm. 4 (julio 1920), pp. 67-69.

» Rossi, L. A. (1999). “Los proyectos intelectuales de José Ingenieros desde 1915 a 1925: la crisis del positivismo y la filosofía en la Argentina". En Ingenieros, J., Ponce, A. (directores). Revista de Filosofía, Cultura, Ciencias, Educación, pp. 1364. Prólogo y selección de textos de Rossi, L. A. Bernal: Universidad Nacional de Quilmes.

»Sarlo, B. (1988). Una modernidad periférica: Buenos Aires 1920 y 1930. Buenos Aires: Nueva Visión.

»Sarlo, B. (2004 [1992]). La imaginación técnica. Sueños modernos de la cultura argentina. Buenos Aires: Nueva Visión.

"Serna Arnáiz, M. (1994). El positivismo latinoamericano. Positivismo y modernismo: encuentros y desencuentros. En Cuadernos Hispanoamericanos, núm. 529/30, pp. 129-137.

»Schuster, F. (1985). “El concepto de ciencia”. En Biagini, H. E. (comp.). El movimiento positivista argentino, pp. 321-332, Buenos Aires: Editorial de Belgrano,

»Sosnowski, S. (editor) (1999). La cultura de un siglo. América latina en sus revistas. Buenos Aires: Alianza.

» Tarcus, H. (2004). "Revistas, intelectuales y formaciones culturales izquierdistas en la Argentina de los veinte". En Revista Iberoamericana, núm. 70, pp. 208-209.

» Taylor, Ch. (2006 [1996]). Fuentes del yo. La construcción de la identidad moderna. Barcelona: Paidós.

» Terán, O. (1986). Estudio preliminar . En José Ingenieros: pensar la nación, pp. 7-104. Buenos Aires / Madrid: Alianza. 
